\title{
Determination of non-hazardous areas in terms of seismic effect for the use of explosives in the open pit in safe conditions
}

\author{
Edward Gheorghiosu ${ }^{1 *}$, Daniela Rus $^{1}$, Ștefan Ilici $^{1}$ and Sorin Mihai ${ }^{2}$ \\ ${ }^{1}$ National Institute for Research and Development in Mine Safety and Protection to Explosion - \\ INSEMEX Petroşani Department of Safety Explosives and Pyrotechnic Aticles, 32-34 G-ral Vasile \\ Milea St., 332047 - Petroşani, Hunedoara County, Romania \\ ${ }^{2}$ SAMAX Romania, Crişcior Locality, No. 146 Calea Zarandului St., Hunedoara County, Romania
}

\begin{abstract}
In addition to the technical and economic advantages of blasting rocks from open-pit mining, this method of extraction can produce effects with a direct impact in the area near the open pit. Blasting works generates effects such as seismic waves that cause vibrations, rock throws, noise and toxic gases. When their intensity and scope are not systematically evaluated and analysed, blasting works can cause serious consequences for people, civil / industrial buildings, the environment, thus affecting the health of the population and the stability / integrity of the buildings / slopes in the vicinity of the mining operations. The paper presents design / determination methods of areas where explosives may / may not be used in conditions of maximum safety in terms of seismic intensity, thus protecting the population and the civil / industrial objectives in the area of the mining work. The obtained results are extracted from a research study carried out for the opening in operation of a new mining deposit, having as reference calculations and theoretical interpretations related to the conditions established for the development of the blasting works.
\end{abstract}

\section{Introduction}

This paper presents the way of forecasting the seismic effect generated by the blasting works that will be carried out in the Colnic Quarry in the Rovina mining perimeter in order to assess the impact of seismic waves on the integrity and stability of nearby civilian objectives. The Rovina perimeter is located in the southern part of the Apuseni Mountains, in the north of the Southern Carpathians and in the west of the Transylvanian Plateau, in the area of the gold quadrilateral near Criscior locality, Hunedoara county. (Fig.1)

The localities of Rovina, Merişor and Bucharest, Crişcior and Zdrapţi are partially included in the exploitation perimeter. For the exploitation of porphyry bodies with copper-gold mineralization from the Rovina-Remetea and Colnic area, the method of exploitation by up-

* Corresponding author: edward.gheorghiosu@,insemex.ro 
to-date mining works will be applied, in the quarry respectively the method with descending stepped and the transport of sterile rocks to the outer (Halda Rovina) and inner dumps the remaining goal of the Colnic quarry).[1]

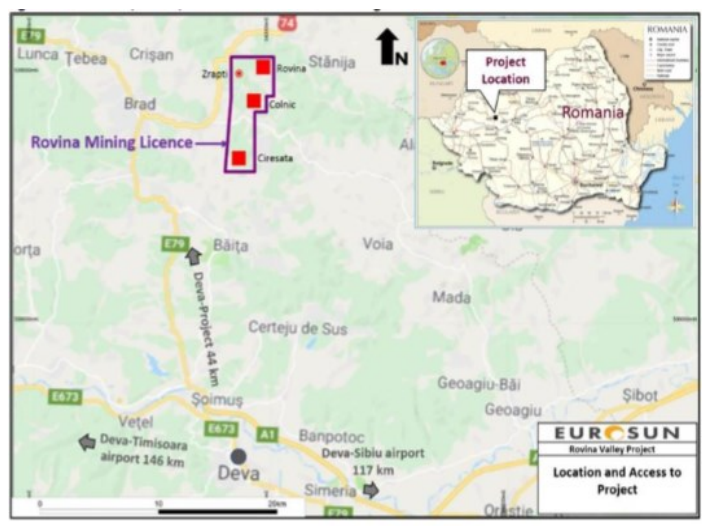

Fig. 1. The Rovina perimeter

The development program of the exploitation in the Rovina perimeter, foresees the opening of two big quarries, respectively the Rovina-Remetea quarry located on the slope of the Baroque valley, and the Colnic quarry located on the Rovina valley, with hearths located at +264 m (Rovina) and +76 m ( Colnic). [1]

For the exploitation of the copper deposit with gold content from the Rovina perimeter, the exploitation method adequate to the geological-technical conditions is the method of exploitation through open mining works, in quarry, in steps with a height of $12 \mathrm{~m}$ - Rovina Remetea and Colnic quarries and through works underground mines - Cireşata V. Gârzii mine. The rock removal in quarries will be done with explosives placed in boreholes.

The following are the geometric and quantitative parameters, under the conditions of using the technique of blasting with well holes, with continuous explosive charges: [1]

- $\quad$ stepped height: $12 \mathrm{~m}$;

- inclination blasting holes: $75 \div 90^{\circ}$;

- number of blasting holes: 15 ;

- number of rows: 2;

- diameter blasting holes: $200 \mathrm{~mm}$;

- $\quad$ burden (w); $4 \mathrm{~m}$;

- distance between holes placed on the same row (a): 5,3 m;

- $\quad$ distance between rows (b): 4,8 m;

- $\quad$ the length of the deepening $\left(\mathrm{L}_{\text {sub. }}\right): 1,2 \mathrm{~m}$;

- $\quad$ length of blasting holes $\left(\mathrm{L}_{\mathrm{g}}\right): 13,2 \mathrm{~m}$;

- length of stemming $\left(\mathrm{L}_{\mathrm{b}}\right): 5 \mathrm{~m}$;

- length of explosives column: 8,2 m;

- explosives used:

- basic explosive charge, explosive Blendex emultion;

- initiation explosive charge, Booster;

- means of initiation: nonelectric initiation sistem;

- the amount of explosive / blasting hole: $297 \mathrm{Kg}$ E TNT (eqhivalent trotil), consist of explosive Blendex emultion and initiation explosive charge, Booster;

- the maximum amount of explosive / delay stage: $297 \mathrm{~kg}$. E TNT (1 blasting hole / delay stage). 
The sequential moves of the rock from the massif will be performed using a network of delayed surface connectors for the initiation of the shock tubes of the primers that transmit the detonation in the blasting holes. [1]

The initiation of the deployment of the blasting will be done from one of the side (left / right) or frontally depending on the conditions in the working stopped. The design and coordination of blasting work must include:

$>$ the moves from the massif of the necessary rock volume, at a granulation corresponding to the technological requirements;

$>$ the protection of civil and industrial objectives in the area against the effects of blasting works (shock wave, throwing pieces of rock and seismic effect).

The seismic effect generated by the blasting works in the quarries is determined by a series of natural and technological factors, which must be taken into account when studying the influence of environmental vibrations on the objectives in the area close to the perimeters where the explosions occur. [2-3]

\section{Methods of evaluation}

Methods for assessing the seismic effect are found in the literature or in European standards and include mathematical expressions that refer to the parameters that characterize seismic waves, such as particle displacement, $\mathrm{u}(\mathrm{mm})$; particle velocity, $\mathrm{V}(\mathrm{cm} / \mathrm{s})$, particle motion acceleration, a $\left(\mathrm{m} / \mathrm{s}^{2}\right) ;[4]$

The use of explosives to moves rocks from the massif has led to the establishment of practical relation, which can be applied by designers and practitioners to determine the safety distances and maximum explosive charge, with which to work safely against the seismic action of blasting works. [5]

As the applicant has devised a technique for sequentially moves the rock from the massif, which is performed by detonating explosive charges from holes at set delay intervals, the assessment was also considered relevant using formulas appropriate to these conditions.

This way of blasting is recommended as the best technical solution to reduce the seismic effect generated by the blasting works in the quarries.

The Austrian standard ONORM S 9020 Building Vibrations was used for the evaluation, which specifies mathematical formulas that can be used to determine the reduces distance or the maximum amount of explosive / delay stage, if the objective is at a distance of more than $50 \mathrm{~m}$ of the place of blasting point [6]:

$$
\begin{aligned}
& \mathrm{D}=17,2 \times \mathrm{L}^{0,625} \\
& \mathrm{~L}=\mathrm{D}^{1,6} / 95
\end{aligned}
$$

$\mathrm{D}=$ the shortest distance at which the maximum amount of explosive can be used / delay stage

$\mathrm{L}=$ maximum amount of explosive / delay stage

A formula correlated with the blasting techniques applied in quarries at this time, with good results in vibration prediction is mentioned in "Safe and Efficient Blasting in Open Cut Mines", Blasting Curses - Orica Mining Services [7]:

$$
v=1140\left(\frac{R}{\sqrt[3]{Q}}\right)^{-1,6} \mathrm{~mm} / \mathrm{s}
$$


where:

$\mathrm{v}$ - the sum vectors of the maximum values of the oscillation velocity $[\mathrm{mm} / \mathrm{s}]$;

$\mathrm{R}$ - the distance between the blasting point and the nearest target to be protected $[\mathrm{m}]$

$$
\text { Q - maximum amount of explosive / delay stage }[\mathrm{kg}] \text {. }
$$

The correlation between the velocity of the oscillations of the soil particles, the degree of seismic intensity and the possible effects on the structures are presented in table 1. [8], [9]

$>$ the allowed oscillation speed is the speed at which it is guaranteed that the previously accepted effects on the construction structures are not exceeded;

$>$ when performing repeated shooting works, the oscillation speed of the soil particles must be within the values of the allowed speed. Oscillation speeds between the allowed and the limit can be accepted only by specialists, in special situations;

$>$ the limit oscillation velocity will be accepted only in special situations, with a single shot when the technological conditions require shooting with larger quantities of explosives;

Table 1.Correlation between velocity of oscillation of the soil particles and their effects on structures

\begin{tabular}{|c|c|c|c|}
\hline \multirow[t]{2}{*}{$\begin{array}{l}\text { Seismic } \\
\text { intensity } \\
\text { categories }\end{array}$} & \multirow[t]{2}{*}{ Effects induced on the structures } & \multicolumn{2}{|c|}{$\begin{array}{l}\text { particle velocity } \\
\mathrm{v} \\
(\mathrm{cm} / \mathrm{s})\end{array}$} \\
\hline & & allowed & limit \\
\hline IV & $\begin{array}{l}\text { Possible damages for village-type buildings, under pressure } \\
\text { pipes, gas and petrol wells, mine shaft, and very fragile } \\
\text { structures. }\end{array}$ & 0.5 & 1.0 \\
\hline $\mathrm{V}$ & $\begin{array}{l}\text { The painting is falling down, small and thin cracks appear in par } \\
\text { get in rural and urban buildings. possible minor damages for } \\
\text { industrial constructions. }\end{array}$ & 1.1 & 2.0 \\
\hline VI & $\begin{array}{l}\text { Cracks in par get on the walls and pieces of par get start to fall } \\
\text { down in rural and urban buildings. also minor damage for } \\
\text { industrial constructions. }\end{array}$ & 2.1 & 4.0 \\
\hline VII & $\begin{array}{l}\text { Significant fractures are occurring in the basic elements of the } \\
\text { rural buildings, great pieces of parget are falling down in urban } \\
\text { buildings and cracks are appearing in industrial constructions. } \\
\text { possible damage for pipes jointing system and fixed - mounted } \\
\text { equipment. }\end{array}$ & 4.1 & 8.0 \\
\hline VIII & $\begin{array}{l}\text { Major factures occur in the resistance elements of rural and urban } \\
\text { buildings. cracks are produced in the resistance elements of } \\
\text { industrial constructions. }\end{array}$ & 8.1 & 16.0 \\
\hline IX & $\begin{array}{l}\text { Crumbing (collapse, falling down) of some joint elements of rural } \\
\text { and urban buildings can occur. fractures can take place in } \\
\text { industrial structures. dams and underground pipes can be } \\
\text { damaged. }\end{array}$ & 16.1 & 32.0 \\
\hline $\mathrm{X}$ & $\begin{array}{l}\text { Rural buildings are destroyed, urban constructions are seriously } \\
\text { damaged and industrial structures are affected seriously by } \\
\text { fracturing and dislocation of resistance elements. }\end{array}$ & 32.1 & 64.0 \\
\hline
\end{tabular}

In this stage, the values of the parameters determined according to the field conditions were taken into account, which consisted mainly of: 
$>$ Total amount of explosive: $4455 \mathrm{~kg} \mathrm{E} \mathrm{TNT}$, determined for blasting, in steps with $\mathrm{h}=12 \mathrm{~m}$, distributed in 15 holes $(\varnothing \mathrm{g}=200 \mathrm{~mm} ; \mathrm{Lg}=13.2 \mathrm{~m})$;

$>$ Quantity of explosive / delay stage: $297 \mathrm{~kg}$ explosive E TNT (trotyl equivalent);

$>$ Reference distances, respectively: $640 \mathrm{~m}$ distance between the nearest objective (the building in Merișor) and the operating limit in the eastern part of the Colnic Quarry and $875 \mathrm{~m}$ the distance between the nearest objective (the building in Rovina) and the area of opening from the northern part of the Colnic Quarry, where the first shooting works will be carried out.

\section{Results}

In order to evaluate the seismic effect in the projected conditions, respectively the shooting with delay steps, the relation (1) was used, which implies this term.

Table 2 shows the distances between the targets and the firing range determined by the different amounts of ETNT explosive detonated at the delay stage.

Table 2. Distance from blasting point

\begin{tabular}{|c|c|}
\hline $\begin{array}{c}\text { The amount of explosive ETNT / } \\
\text { Delay stage } \\
{[\mathrm{kg}]}\end{array}$ & $\begin{array}{c}\text { Distance from blasting point } \\
{[\mathrm{m}]}\end{array}$ \\
\hline 50 & 198 \\
\hline 100 & 306 \\
\hline 150 & 394 \\
\hline 200 & 472 \\
\hline 250 & 542 \\
\hline 297 & 604 \\
\hline 350 & 669 \\
\hline 400 & 727 \\
\hline 450 & 783 \\
\hline 500 & 836 \\
\hline 550 & 888 \\
\hline 600 & 937 \\
\hline 650 & 985 \\
\hline
\end{tabular}

The marking in the table shows that an amount of $297 \mathrm{~kg}$ ETNT explosive per delay stage can be detonated when the nearest target to be protected is at a distance of at least $604 \mathrm{~m}$. The values given in Table 1, indicate that as the amount of ETNT explosive increases with the delay stage, the distance from the targets to be protected should be increased.

In the case of the blasting technique with the use of an explosive quantity of $297 \mathrm{~kg}$ ETNT / delay stage, seismic protection would be ensured at objectives at distances greater than 604 $\mathrm{m}$. It is noted that the determined distance, of $604 \mathrm{~m}$, is less than where the nearest buildings are located, compared to the opening area of the Colnic Quarry $(875 \mathrm{~m})$, where the first blasting works will be carried out. In order to calculate the quantities of explosive ( $\mathrm{kg}$ ETNT), which can be blast at the delay stage, given that the buildings closest to the opening area of the Colnic Quarry are located at $875 \mathrm{~m}$ (concrete situation in the field), applied the relation (2).

The quantities determined for detonation / delay stage at certain distances from the objectives to be protected are shown in Table 3. 
Table 3. Distances from blasting point

\begin{tabular}{|c|c|}
\hline $\begin{array}{c}\text { Distance from blasting point } \\
\text { D [m] }\end{array}$ & $\begin{array}{c}\text { The amount of explosive ETNT / } \\
\text { Delay stage } \\
\text { L [kg] }\end{array}$ \\
\hline 515 & 230 \\
\hline 550 & 255 \\
\hline 600 & 293 \\
\hline 640 & 325 \\
\hline 680 & 358 \\
\hline 700 & 375 \\
\hline 740 & 410 \\
\hline 800 & 465 \\
\hline 840 & 502 \\
\hline 875 & 536 \\
\hline 900 & 561 \\
\hline
\end{tabular}

The marking in the table confirms that at $875 \mathrm{~m}$, the distance at which the buildings are closest to the opening areas of the Colnic Quarry, the expected amount of blasting, respectively $297 \mathrm{~kg}$ of explosive ETNT / delay stage, is considerably lower than the results from the calculation.

Applying the relation (3), for the Colnic Quarry the values of the oscillation velosity of the soil particles included in table 4 resulted.

Table 4. Results for Colnic Quarry

\begin{tabular}{|c|c|c|c|}
\hline $\begin{array}{c}\text { Nr. } \\
\text { isoline }\end{array}$ & $\begin{array}{c}\text { The distance between } \\
\text { the buildings in Merișor } \\
\text { and the isoline } \\
{[\mathbf{m}]}\end{array}$ & $\begin{array}{c}\text { The amount of } \\
\text { explosive ETNT } \\
{[\mathbf{k g}]}\end{array}$ & $\begin{array}{c}\text { Particle oscillation velocity } \\
{[\mathbf{m m} / \mathbf{s}]}\end{array}$ \\
\hline 1 & 513 & & 5,00 \\
\hline 2 & 640 & \multirow{2}{*}{297} & 3,51 \\
\hline 3 & 980 & & 1,77 \\
\hline 4 & 1320 & & 1,10 \\
\hline 5 & 1676 & & 0,75 \\
\hline
\end{tabular}

Using the values from table 4, the zoning of the Colnic Quarry was made (Fig.2), by designing the isolines $(1 \div 5)$ which represent the distances between the nearest buildings, located in Merișor and the limit at which oscillation velocity occur with the resulting values from the calculation. When designing the insulations, it was taken into account that they should pass through the quarry exploitation limits, in the Est side (isoline 2) and West (isoline 5) parts, including the quarry opening area (line 4). 


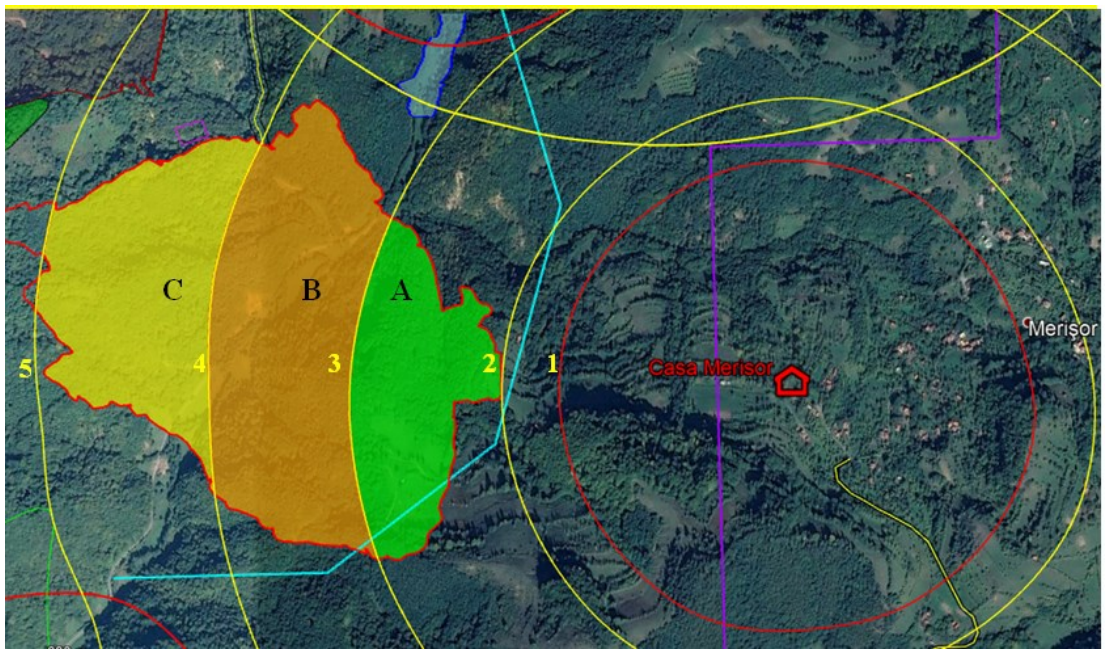

Fig. 2. Colnic Quarry Zoning (reference point for the building in Merișor), (google earth pro)

Explaining the details of Fig. 2, isoline 1, drawn in red at $513 \mathrm{~m}$ distance from the nearest buildings, taken as a reference point (the building in Merișor), represents the distance at which the determined oscillation velocity is $0.5 \mathrm{~cm} / \mathrm{s}$. This value can be considered an allowable threshold according to Table 1, having as minimal effects on the structures "Possible damage to rural constructions, pressure pipes, oil and gas wells, mining wells, very fragile structures." It is observed that the blasting works are carried out after isoline 2, drawn at $640 \mathrm{~m}$, from the nearest buildings to be protected and in conclusion, at longer distances no oscillation velocity with values higher than $0.5 \mathrm{~cm} / \mathrm{s}$.

The isolines $(2 \div 5)$ delimit the areas from the Colnic Quarry (Zone A, B, C), where blasting works with quantities of $297 \mathrm{~kg}$ ETNT explosive / delay stage are performed, which result in the calculation, the production of oscillation velosity with the values mentioned below, having as reference the building mentioned above, as follows:

- Zone A (green), delimited by isolines 2 and 3, area in which the execution of the blasting works induces oscillation velocity in the range of $0.177 \div 0.351 \mathrm{~cm} / \mathrm{s}$;

- Zone B (brown), delimited by isolines 3 and 4, zone in which the execution of the blasting works induces oscillation velocity in the range $0,110 \div 0,177 \mathrm{~cm} / \mathrm{s}$;

- Zone C (yellow), delimited by isolines 4 and 5 , zone in which the execution of the blasting works induces oscillation velocity in the range $0.075 \div 0.110 \mathrm{~cm} / \mathrm{s}$;

Considering that the exploitation of the Colnic Quarry starts from the northern part, it was considered necessary to design the insulations, having as reference (building from Rovina locality) the closest objective to the area where the first blasting works will take place, including the northern quarry exploitation limit.

In this case, the relation (3) was applied, having the results of the values of the oscillation speed of the soil particles included in table 5 .

Table 5. Results for Colnic Quarry

\begin{tabular}{|c|c|c|c|}
\hline $\begin{array}{c}\text { Nr. } \\
\text { isoline }\end{array}$ & $\begin{array}{c}\text { The distance between } \\
\text { the building in Rovina } \\
\text { and the isoline } \\
{[\mathbf{m}]}\end{array}$ & $\begin{array}{c}\text { The amount of explosive } \\
\text { ETNT } \\
{[\mathbf{k g}]}\end{array}$ & $\begin{array}{c}\text { Particle oscillation } \\
\text { velocity } \\
{[\mathbf{m m} / \mathbf{s}]}\end{array}$ \\
\hline 1 & 513 & & 5,00 \\
\hline 2 & 724 & & 2,88 \\
\hline
\end{tabular}




\begin{tabular}{|l|c|c|c|}
\hline 3 & 875 & \multirow{2}{*}{297} & 2,13 \\
\hline 4 & 1265 & & 1,18 \\
\hline 5 & 1685 & & 0,75 \\
\hline
\end{tabular}

Using the values from table 5, the Colnic Quarry zoning was performed (Fig. 3), by designing the isolines $(1 \div 5)$ which represent the distances between the closest building to the quarry opening area, at which oscillation velocity occur with the resulting values. And in this case, when designing the insulations, it was taken into account that they passed through the quarry operating limits, in the part of North side (isoline 2) and South side (isoline 5) including the quarry opening area (isoline 3).

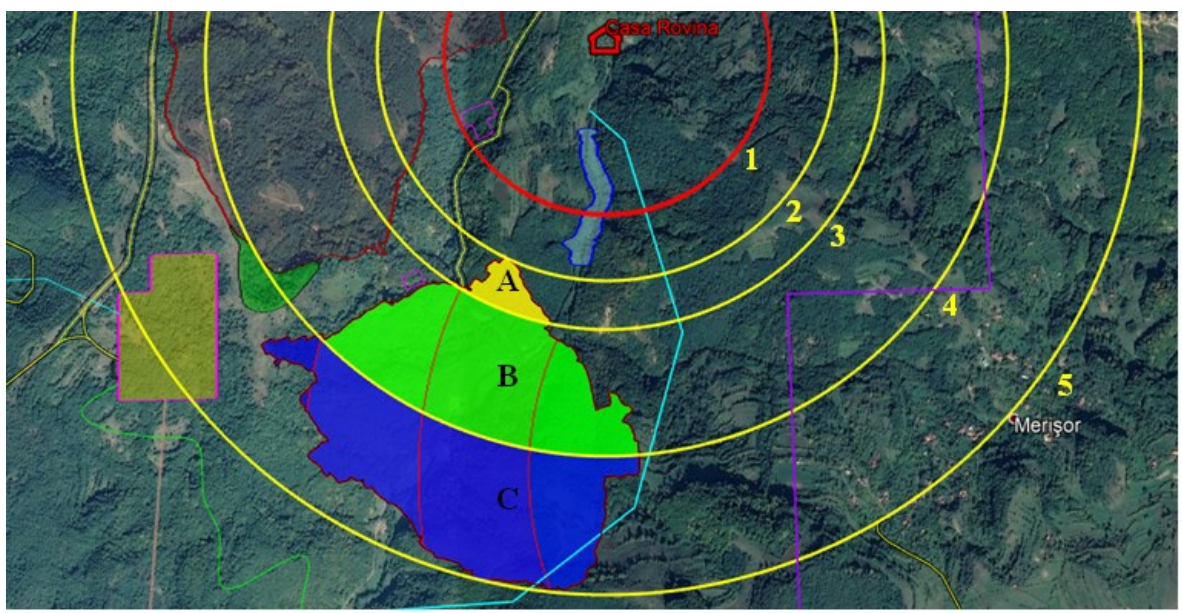

Fig. 3. Colnic Quarry Zoning (reference point for the building in Rovina), (google earth pro)

Explaining the details of Fig. 3, isoline 1, drawn in red at $513 \mathrm{~m}$, distance from the nearest building, taken as a reference point (the building in Rovina), represents the distance at which the determined oscillation velocity is $0.5 \mathrm{~cm} / \mathrm{s}$. This value can be considered an allowable threshold according to Table 1, having as minimal effects on the structures "Possible damage to rural constructions, pressure pipes, oil and gas wells, mining wells, very fragile structures."

It is observed that the blasting works are carried out after isoline 2, drawn at $724 \mathrm{~m}$, from the nearest buildings to be protected. In this situation the oscillation velocity that can occur have values lower than $0.5 \mathrm{~cm} / \mathrm{s}$.

The isolines $(2 \div 5)$ delimit the areas from the Colnic Quarry (Zone A, B, C), where blasting works with quantities of $297 \mathrm{~kg}$ ETNT explosive / delay stage are performed, which result in the calculation, the production of oscillation velocity with the values mentioned below, having as reference the building mentioned above, as follows:

- Zone A (yellow), delimited by isolines 2 and 3, zone in which the performance of the blasting works produces the oscillation velocity in the range $0.213 \div 0.288 \mathrm{~cm} / \mathrm{s}$;

- Zone B (green), delimited by isolines 3 and 4, area in which the blasting works generate oscillation velocity in the range of $0.118 \div 0.233 \mathrm{~cm} / \mathrm{s}$;

- Zone C (blue), bounded by isolines 4 and 5, zone in which, when performing the blasting works, they produce the oscillation velocity in the range $0.075 \div 0.118 \mathrm{~cm} / \mathrm{s}$; 
It should be mentioned that in the evaluations of the seismic effect presented in the paper, the use of applications that include as terms, empirical coefficients corresponding to certain geological conditions were not considered.

Their use would have influenced the level of probability of the subsequent confirmation of the evaluation results, specifically in the development of this process. Each area in which blasting works with explosives are carried out and the environment in which seismic waves propagate has its particularity.

The geological characteristics of the area are highlighted by in situ measurements, performed with specific equipment.

\section{Conclusions}

The preliminary information obtained as a result of the work was obtained by applying empirical mathematical relations that must be confirmed by seismic monitoring of the blasting works performed in the Colnic Quarry.

The results of the seismic assessment that was the subject of a theoretical study, applying analytical methods, for the conditions designed by the applicant, do not highlight a risk situation that does not allow the start of operation in the Colnic Quarry. However, variable factors such as terrain morphology, atmospheric conditions, physical and mechanical characteristics, etc., can influence the appearance of differences between the results obtained by calculations and the results that will be obtained by concrete measurements "in situ".

In this regard, it is recommended that in the first stage an experiment be carried out in the opening areas of the quarry, by carrying out control blasting in which to use minimum quantities of explosive per delay stage, which may be even smaller for the beginning than those designed. The blasting work will be done on the basis of work programs that include specific safety measures that are required.

In order to open the database with concrete results obtained in real conditions, the control blast will be monitored seismically by placing seismographs in the measurement locations in the area adjacent to the quarry and at the buildings to be protected at different distances from the explosion site.

If the values of the parameters measured at the blasting works exceed the safety thresholds for seismic protection, the operator of the blasting works will identify and apply technical solutions to reduce the seismic effect, to carry out activities with minimal impact on neighborhoods.

The definition of the blasting conditions must be updated after evaluating the results of the "in situ" measurements carried out in a certification process, using the test infrastructure of an accredited laboratory, which has a sufficient number of high-performance equipment (seismographs), specific this activity.

\section{References}

1. INSEMEX Petrosani, Theoretical study on the evaluation of the seismic effect and of the overpressure in the shock wave front, generated by the blasting works carried out in the quarries from the Rovina mining perimeter (Colnic and Rovina-Remetea quarries) (2020)

2. E. Gheorghiosu, G. A. Găman, E. Ghicioi, A. Kovacs, G.D Vasilescu, Guide for evaluating the seismic effect generated by blasting works in quarry, (INSEMEX 2019)

3. E. Gheorghiosu, A. Kovacs, G. D. Vasilescu, D. C. Rus, F. Radoi, E.E.M.J. 18, 817-824 (2019)

4. E. Gheorghiosu, G. D. Vasilescu, E. Ghicioi, A Kovacs, D. C. Rus, SGEM 3, 559-566 (2015) 
5. F. Radoi, E. Gheorghiosu, A Kovacs, G. D. Vasilescu, S. Bordoș, C. R. Cioara, SESAM 2, (2017)

6. ONORM S 9020, Austrian Standard, Building Vibrations, (1986)

7. ORICA, Safe and Efficient Blasting in Open Cut Mines, Technical Services, (ORICA, 2008)

8. STAS 3684-71 - Seismic intensity scale (1971)

9. E. Dumitru, A. Bujor, Seismology of controlled explosions in industry, (Technical Publishing House, Bucureşti 1987)

10. Google Earth Pro 